\title{
Respecting Our Students
}

Andy Gavrin

Citation: The Physics Teacher 53, 412 (2015); doi: 10.1119/1.4931009

View online: $\mathrm{http}: / / \mathrm{dx}$.doi.org/10.1119/1.4931009

View Table of Contents: http://aapt.scitation.org/toc/pte/53/7

Published by the American Association of Physics Teachers
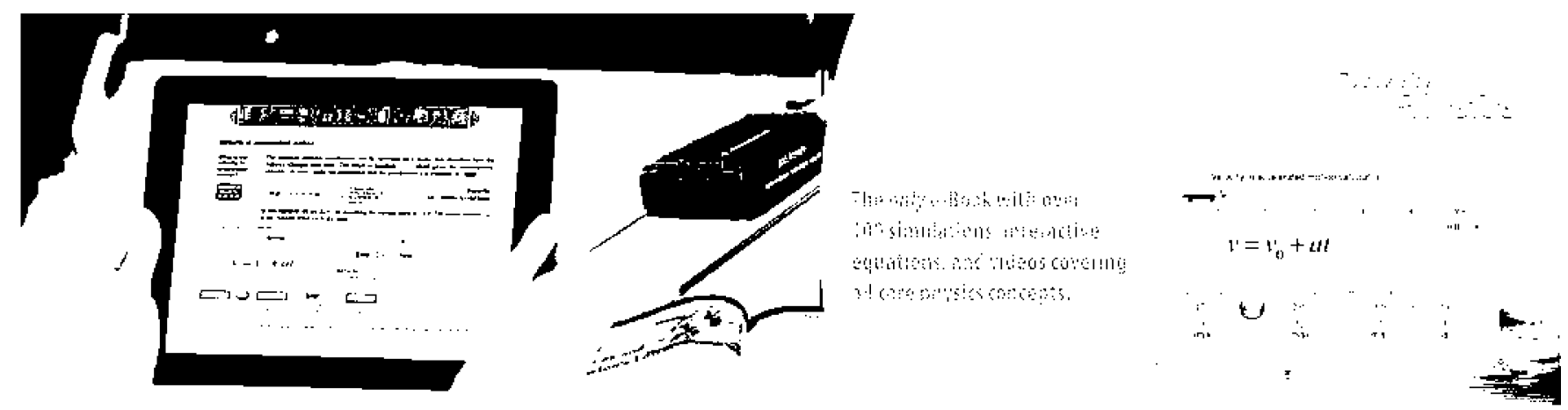


\section{Respecting Our Students}

IUPUI, Indianapolis, IN

$\mathrm{G}$ iving our students the respect they deserve will improve their performance, our mutual interactions, and our satisfaction as teachers. This is obvious to many $T P T$ readers, but there are times when we all, myself included, forget. There are times when our judgment is clouded by institutional culture, or our best intentions are subverted by the vexations of our roles as instructors. This essay is based on my own experience teaching physics (primarily at a public urban university, primarily at the introductory level), and on conversations with many colleagues here and elsewhere. I hope this essay will serve as a reminder to all of us that we must treat our students with respect, and that the rewards of doing so are worth the effort of rethinking some of our behaviors.

This essay is not an indictment of every physics course. Many of us have excellent working relationships with our students. This is not about blaming faculty. Our students, our administrators, and the history of physics instruction all contribute to the lapses in respect that occur. This is certainly not an argument to make physics easier. Rather, this essay is an effort to explore how our teacher-student relationships fall short of ideal, the reasons behind these shortcomings, and the ways we can improve.

This essay is squarely in the realm of "the art" of teaching physics. There is a vast literature of "positive psychology."1 Studies have shown that improved academic outcomes are associated with hope ${ }^{2}$ and optimism, ${ }^{3}$ and linked these to positive mental states such as "flow." ${ }^{4}$ There is also a substantial literature linking "instructor misbehavior" with adverse student outcomes. ${ }^{5}$ This literature is interesting, but I do not consider it essential that all physics teachers become experts in this area. I, at least, do not need "proof" to convince me to be respectful to my students. This is in part what I consider the "art" of teaching physics. It is a choice I have made because it "feels right." I do not provide proof to my physician that she should treat me with respect as a patient; in turn, I do not ask for proof that I should respect my students.

\section{Defining terms}

One definition of "respect" is "a feeling or understanding that someone or something is important, serious, etc., and should be treated in an appropriate way." 6 By this standard, there can be little doubt that our students deserve respect. They are important; there can be no teaching without them. They are serious. As individuals they may not always behave seriously, but as a group, their needs require our serious effort. We must treat them appropriately. What would be inappropriate? Let's skip the obvious. In my view, any treatment that reduces a student's motivation to learn is inappropriate. Any treatment that damages a student's confidence is inappropriate. Any treatment that makes physics a burden rather than a joy is inappropriate.

\section{What disrespect looks like}

Some forms of disrespect are obvious: faculty should arrive on time and end on time, just as we wish our students to be punctual. Faculty should not demean a student or, equivalently, a question a student has asked. Other forms are subtler. A student asks, "How do you solve this problem...?" To be concrete, let's say it involves a ballistic pendulum. We answer, "Well, you just set the initial momentum equal to the momentum after the collision, then use conservation of energy." Perhaps we give additional details, or ask some leading questions. What is inappropriate? It is the word "just." It's verbal filler to us, but to the student it says, "This is so easy, you shouldn't have to ask." Here is my first suggestion: we should purge words like "just," "only," and "simply" from the vocabulary we use with students. "Straightforward" has to go as well, and "trivial" is completely out. By remembering that our students are learners, not experts, we can treat them with respect.

Sometimes, the inappropriate message is nonverbal. During lecture, we pose a question: "What is the direction of the magnetic force on this charge?" We pause, look around, ask, "Anybody?" look around again, then say, "Probably lots of you know, the force is into the board." The problem here is timing. ${ }^{7}$ For students just learning the subject, it could take 30 seconds to mentally work through the right-hand rule (twice, to be careful). That's really not bad. But in our haste, and our expertise, we forget. We only give 10 seconds, and our body language is screaming, "Come on! This is easy!" When we do give the answer, even with a smile, our tone may say, "You people are so slow."

Occasionally, we simply must guard against our own enthusiasm. Ever think up a "really clever" problem for an exam? To us, it is still the same physics, and fun to boot. Our students may feel like they have been ambushed.

\section{Root causes}

How did we get here? Large classes are at particular risk. When we can't learn all our students' names, it is hard to treat them as individuals. When we can barely see the students in back, it is impossible to understand their nonverbal cues. Our training as scientists exacerbates this. Intrigued by data from Scantron exams, online homework, etc., we may unwittingly begin to view our students as a system we can model, rather than as individuals who deserve respect. We must guard against this attitude.

Even in small classes, when we know our students, time can be an enemy in several ways. If we teach the same subject for several years, time can blur the lines between semesters. Deep down, our gut is saying, "I have explained this a dozen times," even when our head knows we have only explained it to these students once. The time pressure that faculty feel 
can also encourage our (very human) tendency to stereotype. Individuals become categories like "athlete," "international," or even "good student." These pressures exist; we cannot wish them away, but we must overcome them. Even when our students "look like" a group, or act like a "type," we must treat them with the respect due to people.

Administrative requirements also contribute. Highstakes testing, student evaluations, assessment mandates, and required grading policies all promote a sense that our relationships with students can be measured by a handful of numbers. Our students are subject to similar feelings when we present them with multiple-choice exams and surveys. Multiple-choice clicker questions can exacerbate this if they are not used to spark discussion. They are struggling with new ideas, many abstract and subtle. Then we reduce their intellectual progress to a percentage and a class average. This doesn't mean we shouldn't assess our students, or that statistical measures are wrong. It means that we must be vigilant in our efforts to respect our students, particularly when we discuss the numbers with them. We can emphasize the range in addition to the average, and always express a willingness to go into more detail in person.

Students are not blameless either. In fact, some are among the worst offenders. They don't ask questions, and they sleep in class. They use the web to look up answers. They don't do the reading; they don't come to office hours; and they whine about their grades. We offer them physics, which we love; they reduce it to a "formula sheet" and accuse us of boring them. All of that is true, and more. I do not wish to "blame the victims" here, any more than I wish to blame the faculty. My goal is to spark discussion on how we can change.

\section{Giving respect, gaining trust}

Nevertheless, we are the professionals in this situation. We must rise above these slights and treat the offenders with respect. They are our students, and it is our responsibility to teach them. Sure, if we had better students, they would learn more. That would not mean we were better teachers, just luckier ones. The most challenging students make us the best teachers, just as the most challenging problems make them the best learners.

To overcome many of the challenges I raise in this essay, we must take responsibility for creating and maintaining our relationships with our students. There is no better place to start than with the first day of class, and there is no better tool than honesty. I devote the first class of each semester to building that relationship. ${ }^{8}$

Day $1, t=0$ : I introduce myself, give my contact information, and tell students how they can address me (by a variety of informal, respectful choices), then, after less than $90 \mathrm{sec}$ onds, I display my "mission statement" for the course:

- My Goal: To help you become good, successful engineers and scientists.

- Translation: to set you up for better jobs when you graduate, and better careers after that.
This may seem obvious to us, but it is not obvious to our students. Many believe that our goal is to "weed out" their ranks. I stress that improving their future prospects is our shared goal, and I promise that everything I do, say, and assign is guided by that goal. I let my students know that if they do not understand how something I do supports that goal, they have a right to ask and to expect an answer. The next slide describes the essential elements in reaching our goal:

- I will ask you for a lot of time.

- I will ask you to strain your brain.

- I will do the same.

- Together, we will succeed.

There is a lot more that I do during the first class. Much of it is devoted to engaging my students in a conversation about what things they have learned well (Video games? Sports? A musical instrument?) and how they have learned it (Hours of practice? Alone or with others?). This boosts their confidence and reinforces the messages of hard work, long hours, and cooperation. I am also establishing classroom norms (we will be having discussions, answering questions, using clickers...). By the end of class, I have emphasized the message that "Together, we will succeed" several times. This leads to another key to respectful student-teacher relationships: leadership.

As instructors, we are in positions of leadership. We cannot renounce our leadership, and we ignore it at our peril. As leaders, we have a responsibility to motivate students when they are not motivated. If they are unfocused, it is our responsibility to help them focus. If they are bored, we must intrigue them, and if they are scared, we must reassure them. It is our responsibility to build the team, to define the goals, to establish the structure, and to create, communicate, and implement the plans for success. This does not mean we have to do all of the work; the students are on our team. They have responsibilities, but we must assign them. They expect leadership from us; we must not let them down.

\section{Maintaining trust and respect}

Once trust and respect have been established, we must hold those dear. We must never abuse our students' trust. This, too, may seem obvious, but it is easy to slip. There are big slips, of course, such as capriciously changing assignments. There are many small slips, though, such as assigning an expensive textbook then casually mentioning that we do not think it's very good. Misusing class time is another way to lose our students' trust. For instance, telling them that class will meet, then, when they show up, giving them a 30-minute survey from which they can opt out and which will not affect their grade. Many students will appreciate the free time, but what about the others? I made this mistake once, and was very politely, but firmly, taken to task by a student who had made a long drive to attend.

We are asking our students to spend their time, their effort, their money, and their emotion on our courses. We must 
reciprocate where possible and explain where necessary. There are a thousand large and small things we can do.

- Do we want our students to be enthusiastic about studying physics? Of course. Will they be more enthusiastic than we are about teaching it? Not likely. We love physics! We should oversell it! Exclamations, big gestures, and a wide smile are free!!

- Exams are a huge issue. We don't expect perfection, so we give partial credit. How? Many of us do it with a red pen, which we use to highlight the mistakes. The overall message is, "You did a lot of stupid stuff" This may be true, but is it appropriate? Does it increase confidence and motivation? Why not use a blue pen, give positive credit, and write the words "Great job!" on occasion?

- Let's say an exam had a class average of $67 \%$. Good! We let the class know how proud we are of them (last semester, a similar test had an average of $62 \%$ ). But students may interpret this average as implying an attitude: "Missing a third of the subject is the best I hope for from you people." Why not design the exam with a target class average in the high 70s? That will still give plenty of resolution.

- If class average is significantly lower than we expected, who is to blame? Answer: it doesn't matter. We should sincerely and publicly accept the blame. Not because we did something wrong, but because this is a better way to build morale than blaming our students, even implicitly. If the class, on average, has not studied well, it is up to us to motivate them to do better.

- As the semester progresses, attendance may decline. How frustrating! One particularly bad day we tell the class, "Poor attendance is hurting a lot of your grades." Who did we scold? The ones who showed up! Why not say, "Thanks to everyone who is here today. I know there's a lot to do, and I appreciate your focus on this class."

\section{Is this spoon feeding? Lowering standards?}

No. Many of us did not need the courtesies and considerations, but that is a misleading detail. We are a highly select group, in no way representative of our student population. As students, we were highly motivated and self-selected. We came to school already excited about physics and, in most cases, determined to succeed.

Context also means a great deal. We do not expect the same behavior from a six-year-old as we do from a high school student. We should not expect the same physical insight from a college freshman as we do from a graduate student, nor should we expect the same academic sophistication, or the same level of professionalism. We must remember, our students are learners; they are not "done" yet.

\section{Who benefits?}

We all do. When we respect students as learners, we help them respect us as teachers. When we earn and keep our students' trust, we establish the relationship needed for them to follow us, even through tough challenges with uncertain outcomes. When we get these things right, we create the opportunity to focus our energies on understanding and appreciating the beauty of physics. When we get these things right, we spend less time and energy on policies, fairness, and blame. When we get these things right, we benefit as much as our students. When our students trust us and follow us, we can take them further along the road we want them to travel. What could be more satisfying as a teacher?

What do physics teachers teach? We teach students.

\section{References}

1. Martin E. P. Seligman and Mihaly Csikszentmihalyi, "Positive psychology: An introduction," Am. Psychol. 55, 5-14 (2000).

2. J. Ciarrochi et al.,"The impact of hope, self-esteem, and attributional style on adolescents' school grades and emotional well-being: A longitudinal study," J. Res. Pers. 41, 1161-1178 (2007)

3. C. S. Carver and M. F. Scheier, "Optimism, pessimism, and self-regulation," Optimism and Pessimism: Implications for Theory, Research, and Practice, edited by E. C. Chang (American Psychological Association, Washington, DC, 2001), pp. 31-51.

4. M. Csikszentmihalyi, Flow: The Psychology of Optimal Experience (Harper \& Row, New York, 1990).

5. Alan K. Goodboy and S. A. Myers, "Revisiting instructor misbehaviors: A revised typology and development of a measure," Comm. Educ. 64, 133-153 (2015).

6. http://www.merriam-webster.com/dictionary/respect.

7. Not only is this disrespectful, but it is poor pedagogy. See, e.g., M. B. Rowe, "Wait time and rewards as instructional variables: Their influence on language, logic, and fate control," J. Res. Sci. Teach. 11 (2), 81-94 (1974).

8. What follows was developed for introductory courses with enrollments of 120 - 180 students, but it is applicable, with adjustments, to any setting.

Andy Gavrin is associate professor and chair of Physics at Indiana University Purdue University Indianapolis (IUPUI), and a member of IUPUI's University College faculty. He is a co-developer of the Just-in-Time Teaching method and an award-winning teacher. He is also director of "Bridges to the Baccalaureate in Central Indiana," an NIH-funded initiative to increase minority participation in the biomedical and life sciences. He is a member of the Project Kaleidoscope 21st Century Faculty and of Indiana University's Faculty Colloquium for Excellence in Teaching. His research is focused on the use of technology in science education. He received his $B S$ in physics from MIT, and his MS and PhD in physics from The Johns Hopkins University. He joined the faculty of IUPUI in 1995.

agavrin@iupui.edu 